

\section{EXCHANGE}

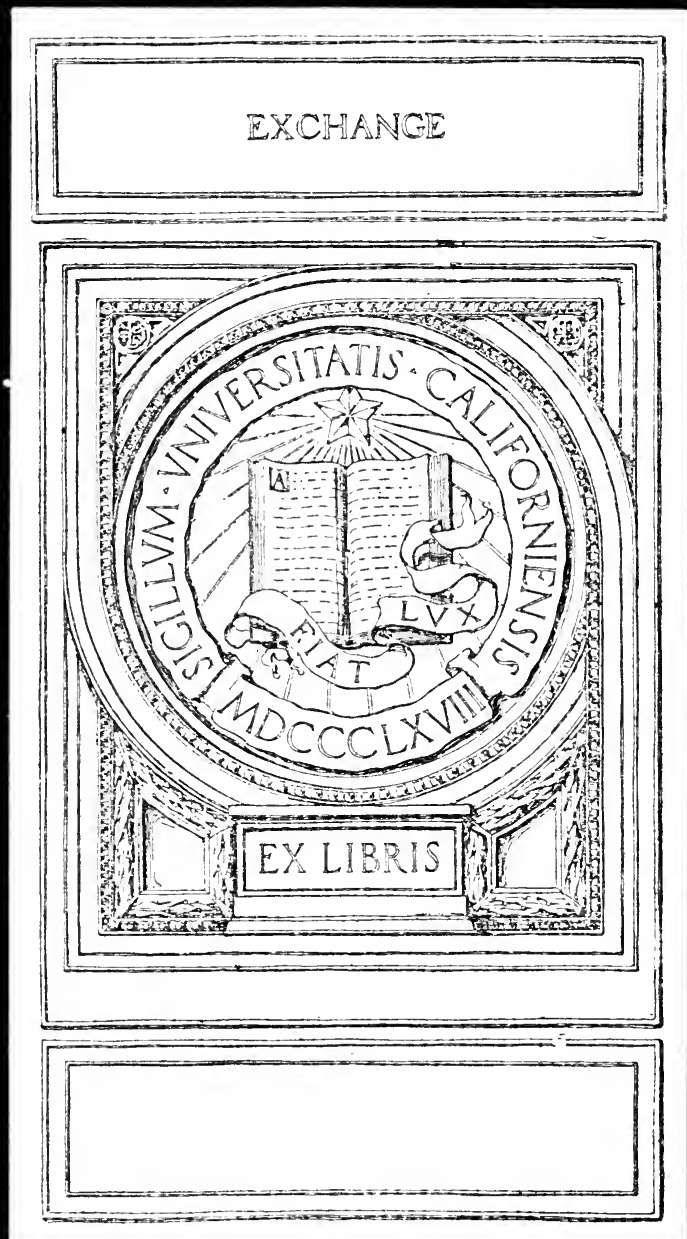

8061 'II NHT ity

$x$ N 'asnoeiks - solg piork

1әpu!g

to/ydure 
CHLORINATION AND THE FORMATION OF CHLOROAMINES BY MEANS OF NITROGEN TRICHLORIDE

BY

GEORGE HOPKINS COLEMAN

B. S. Greenville College, 1915

M. S. University of Illinois, 1919

THESIS

SUBMITTED IN PARTIAL FULFILLMENT OF THE REQUIREMENTS

FOR THE DEGREE OF

\title{
DOCTOR OF PHILOSOPHY
}

\author{
IN CHEMISTRY
}

IN

THE GRADUATE SCHOOL

OF THE

UNIVERSITY OF ILLINOIS

1921

EASTON, Pa.:

Éschenanach Printing Company 
$\because \quad$ 
CHLORINATION AND THE FORIMATION CF CHLOROAMINES BY MEANS OF NITROGEN TRICHLORIDE

BY

GEORGE HOPKINS COLEMAN

B. S. Greenville College, 1915

M. S. University of Illinois, 1919

\section{THESIS}

SUBMITTED IN PARTIAL FULFILLMENT OF THE REQUIREMENTS

FOR THE DEGREE OF

DOCTOR OF PHILOSOPHY

IN CHEMISTRY

IN

THE GRADUATE SCHOOL

OF THE

UNIVERSITY OF ILLINOIS

1921

EAston, PA.:

Eschendach Printing Company 


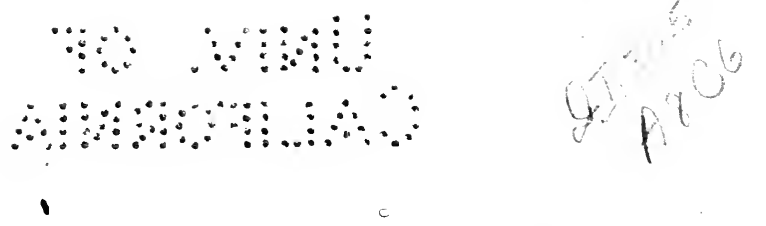


ACKNOWLEDGMENT.

The writer wishes to express his appreciation for the invaluable assistance of Professor Noyes, who suggested the problem and under whose direction this research was done. 
. 


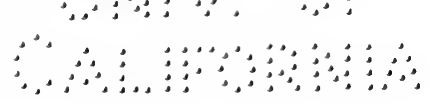

\section{CHLORINATION AND THE FORMATION OF CHLORO-AMINES BY MEANS OF NITROGEN TRICHLORIDE.}

\section{Introduction.}

The investigation was first undertaken in the hope that it might have a bearing on the general question of the positive and negative character of atoms in combination.

A study of the reaction between nitrogen trichloride and ethyl bromide was made with the thought that it might yield triethylamine and free chlorine and bromine, or perhaps a chlorobromine compound. A reaction of this kind would, of course, be of much interest in relation to the general problem. Ethyl iodide was first used, but it was found very difficult to control the reaction. The work was therefore carried out with ethyl bromide.

No evidence was found of the formation of an amine. The products of the reaction were ammonium chloride, nitrogen, chlorine, bromine, and a small amount of a high-boiling liquid residue left upon distillation of the ethyl bromide. That the nitrogen trichloride did act as a chlorinating agent to a slight extent was evidenced by an analysis of the three principal fractions of the high-boiling residue. The results seemed to indicate that these products were not the same as those found when Lescoeur ${ }^{1}$ studied the action of chlorine on ethyl bromide.

To determine whether or not nitrogen trichloride differs from free chlorine in its chlorinating action, the investigation was continued. Ethyl chloride was used in place of ethyl bromide in order to simplify the identifications of the products.

With the thought of extending the work to a different class of compounds, the reaction of nitrogen trichloride was also tried with toluene, with benzene, and with benzyl chloride. In each case, a very unexpected result was obtained in that; along with other products of the reaction, small amounts of chlorinated amines were formed.

\section{Theoretical.}

I. Chlorination.-The work with nitrogen trichloride and ethyl chloride was carried out as that with the ethyl bromide had been, without exposure to light other than dim artificial light. The products of the

${ }^{1}$ Lescoeur, Bull. soc. chim., 29, 483 (1878). 
reaction were similar to those obtained with the ethyl bromide. The most interesting and significant feature of the work with this compound, however, was the fact that, in addition to the usual products of the action of chlorine on ethyl chloride, the high-boiling residue contained a relatively large amount of ethylene chloride.

It has been quite well established that ethylene chloride is not a product of the chlorinating action of free chlorine on ethyl chloride in the absence of a catalytic agent. As the products of this reaction, Regnault ${ }^{2}$ found ethylidene chloride, cogether with several higher chlorinated derivatives of ethane, but no ethylene chloride. Damoiseau, ${ }^{3}$ although his experiments were performed at a higher temperature, found no ethylene chloride. Geuther ${ }^{4}$ apparently found traces of ethylene chloride in his product, but thought it was due to impurities in the ethyl chloride used. Städel ${ }^{5}$ prepared $5 \mathrm{~kg}$. of the reaction product, which on careful fractionation, gave no evidence of ethylene chloride. Denzel ${ }^{6}$ also secured the same result. However, Victor Meyer and Müller ${ }^{7}$ did prepare ethylene chloride from ethyl chloride by heating equivalent amounts of antimony pentachloride and ethyl chloride at $100^{\circ}$ in sealed tubes. They also prepared ethylene bromide from ethyl bromide and bromine, with iron filings as a catalytic agent.

As mentioned above, the work with the aromatic compounds was undertaken with the thought of studying the chlorinating action of nitrogen trichloride on a different class of substances. In the case of toluene, it was found that the high-boiling residue left on distillation of the toluene consisted of a mixture of monochloro-toluenes and benzyl chloride together with higher chlorinated products. Hentschel ${ }^{8}$ found benzene hexachloride as the product of the action of nitrogen trichloride on benzene in the sunlight. It might be pointed out in this connection that sunlight decomposes nitrogen trichloride rapidly. Probably this product was formed by the action of free chlorine on the benzene. Benzene hexachloride was also found to be the main chlorination product of the trichloride with benzene in this investigation. Although in most cases, the reaction was carried out in the dark, an excess of chlorine was present in the solution soon after its preparation, as a result of the decomposition of the trichloride.

II. Chloro-amines.-In all the reactions studied, a white precipitate containing ammonium chloride was formed. In the case of toluene, of benzene and of benzyl chloride, when this white precipitate was dissolved in water and an alkali was added, a mixture of insoluble amines separated at once. With benzene and with benzyl chloride, the white precipitate

${ }^{2}$ Regnault, Ann. Chem. Pharm., 33, 312 (1840).

${ }^{3}$ Damoiseau, Compt. rend., 63, 60 (1876).

4 Geuther, Z. Chem., 7, 147 (1871).

'Städel, Ann., 195, 182 (1879).

- Denzel, ibid., 195, 204 (1879).

${ }^{7}$ Victor Meyer and Müller, Ber., 24, 4249 (1891).

${ }^{8}$ Hentschel, Ber., 30, 1436 (1897). 
was found to contain the hydrochlorides of the amines only when the solutions had been exposed to sunlight, or after it stood for a long time. But, in all cases, if the solutions from which the precipitate had been removed were shaken with conc. hydrochloric acid, amines were found in the aqueous solution.

The properties of this intermediate compound present in the original solutions are illustrated in the work with benzene. It was found that it did not possess basic properties and was not easily hydrolyzed or reduced. When it was shaken with conc. hydrochloric acid, free chlorine was liberated and aniline derivatives were formed. This intermediate compound is probably an $\mathrm{N}$-chloro-amine, $i$. e., a chloro-amine in which the chlorine is combined with the nitrogen.

The work of Bender ${ }^{9}$ is typical of that done by several investigators on the preparation and rearrangement of $\mathrm{N}$-chloro-amines or substituted nitrogen chlorides. Nchloro-acetanilide was prepared from acetanilide and calcium hypochlorite. When heated to $172^{\circ}$, this compound rearranged to give $p$-chloro-acetanilide. In a study of the characteristic rearrangements of the substituted nitrogen halides, Chattaway and Orton ${ }^{10}$ prepared a series of compounds in which the halogen of a chloro-or bromo-amine, $\mathrm{C}_{6} \mathrm{H}_{5} \mathrm{NRX}$, rearranged successively to compounds with the halogen in positions 4,2 and 6 . The chloro-amine $\mathrm{C}_{6} \mathrm{H}_{2} \mathrm{X}_{8} \mathrm{NRX}$, which was finally obtained did not undergo further rearrangement.

The action of nitrogen trichloride on aniline, on methyl aniline and on dimethyl aniline has been studied by Hentschel. ${ }^{11}$ When equimolecular parts of aniline and a solution of nitrogen trichloride in benzene react, trichloro-aniline is formed. This compound may also be formed by passing chlorine into a suspension of aniline hydrochloride in benzene. Methyl aniline similarly gives trichloro-methylaniline. Dimethyl aniline gives a product the structure of which was not determined.

Beilstein and Kurbatow ${ }^{12}$ have prepared trichloro-aniline and tetrachloro-aniline by chlorination of mono and dichloro-aniline. Pentachloro-aniline has been prepared by Langer ${ }^{13}$ by passing chlorine into an ether solution of dichloro-aniline.

Without introducing the question of positive and negative valence, it may be suggested as a possible explanation of the mechanism of the formation of the amines that the nitrogen trichloride adds to the benzene ring to give a compound, $\mathrm{C}_{6} \mathrm{H}_{6} \mathrm{NCl}_{2}$. Cl. This may be followed by the loss of hydrochloric acid to give a chloro-amine, $\mathrm{C}_{6} \mathrm{H}_{5} \mathrm{NCl}_{2}$. A possible explanation of the transformation produced by conc. hydrochloric acid may be the following. One molecule of hydrochloric acid adds to the nitrogen and is followed by the loss of a molecule of chlorine. This would leave an $\mathrm{N}$-monochloro-amine which by a similar process is changed to the true amine.

\footnotetext{
${ }^{9}$ Bender, Ber., 19, 2272 (1886).

${ }^{10}$ Chattaway and Orton, Ber., 32, 3572 (1899).

${ }^{11}$ Hentschel, Ber., 30, 2643 (1897).

12 Beilstein and Kurbatow, $A n n$., 196, 230 (1879).

13 Langer, ibid., 217, 120 (1882).
} 
<smiles></smiles><smiles>[R][AlH][CH]Cl</smiles>

One of us ${ }^{14}$ has shown that nitrogen trichloride and hydrochloric acid yield ammonium chloride and chlorine quantitatively, even in the absence of water. A similar explanation of the mechanism of the reaction was given.

The amines were extracted with ether after the addition of alkali to the aqueous solutions, and subsequently studied. From the method of formation and the presence of an excess of chlorine in the solutions a mixture of chlorinated amines was to be expected. This proved to be the case, the products evidently consisting of mixtures of chlorinated anilines and toluidines, respectively. These products when first obtained by evaporation of the ether from a dry ether solution, were viscous liquids. In the case of the product from benzene, a crystalline substance was obtained by recrystallization from ether and ligroin. The toluene product behaved quite peculiarly in that, on standing a few days, it changed to a dark brittle rosin-like solid. The amine mixture obtained from benzene did not do this. If chlorine had substituted in the side chain of the toluene molecule, such a change could be explained by a reaction between the chlorine of one molecule and the amino group of another. With this in mind, the action of nitrogen trichloride on benzyl chloride was tried. The viscous liquid mixture of amines obtained from this reaction solidified in a few days as that from toluene had done. The explanation given then seems probable.

\section{Experimental.}

I. Nitrogen Trichloride and Ethyl Chloride.-Various methods for the preparation of nitrogen trichloride were tried. The method which was most satisfactory and the one finally used was the following. A solution of ammonium sulfate or ammonium nitrate, together with a suitable solvent for the nitrogen trichloride (in this case ethyl chloride itself was used), was surrounded with a freezing mixture at $-10^{\circ}$ to $-20^{\circ}$, and the chlorine was passed into this solution at the rate of 0.2 to $0.4 \mathrm{~g}$. per minute. The solutions were kept in intimate contact by means of a stirrer operated by a small motor. When the reaction was complete, the ethyl chloride solution was separated from the aqueous layer and dried with calcium chloride. Samples were taken and the remainder of the solution was sealed in thick-walled glass tubes and left in the dark for from 10 to 20 days.

${ }^{14}$ Noyes, J. Am. Chem. Soc., 42, 2173 (1920). 


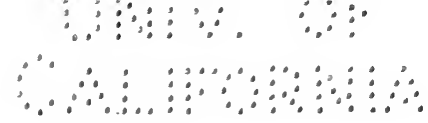

In the analysis of the solutions, the nitrogen was determined with conc. hydrochloric acid, according to the reaction $\mathrm{NCl}_{3}+4 \mathrm{HCl}=\mathrm{NH}_{4} \mathrm{Cl}+3 \mathrm{Cl}_{2}$, a method developed by one of us $^{15}$ and found to give better results than the usual sodium sulfite reduction. The ammonia was then determined by distillation from an alkaline solution. The chlorine was determined in another sample by Volhard's method, after it was reduced with sodium sulfite and treated with just enough potassium permanganate to oxidize the excess of sulfite.

In all, $1105 \mathrm{~g}$. of solution containing $504.4 \mathrm{mg}$. atoms of nitrogen was prepared and used. From this amount the high-boiling residue formed in the reaction, on careful fractionation, gave the following fractions.

TABLE I.

Fractionation of High-Boiling Residue.

$\begin{array}{lccc}\text { Temp. } & \begin{array}{c}\text { Vol. } \\ \text { Cc. }\end{array} & \begin{array}{c}\text { Temp. } \\ \text { C. }\end{array} & \begin{array}{c}\text { Vol. } \\ \text { C. }\end{array} \\ 50-58 & 0.25 & 81-84 & 1.00 \\ 58-62 & 0.50 & 84-150 & 0.20 \\ 62-72 & 0.40 & 150-175 & 0.50 \\ 72-76 & 0.20 & 175-190 & 2.00 \\ 76-81 & 0.25 & \text { Residue above } 190^{\circ}, 0.70\end{array}$

Several of the usual methods for distinguishing between ethylene chloride and ethylidene chloride were tried with the known substances, but with the very small amounts with which it was necessary to work in the case of the fractions obtained above, none of these was found to be satisfactory. Finally a method of differentiation was developed in which very small quantities could be used. This was based on the rates of hydrolysis of the two chlorides by alkali, followed by oxidation of the product of hydrolysis with alkaline permanganate and the determination of the oxalate formed by titration with standard permanganate in hot acid solution. Ethylidene chloride was found to hydrolyze more rapidly than ethylene chloride and to give very much less oxalate on oxidation. The titration for $0.2 \mathrm{cc}$. each of ethylene and ethylidene chloride took $20.08 \mathrm{cc}$. and $3.05 \mathrm{cc}$. of standard permanganate solution respectively. The fractions of the chlorinated product corresponding to the boiling points of ethylene and ethylidene chloride behaved in every way like those of the known substances. The $81-84^{\circ}$ fractions required $18.00 \mathrm{cc}$. of permanganate solution for oxidation of the oxalate formed, the $58-62^{\circ}$ fraction, $3.90 \mathrm{cc}$. only.

II. Nitrogen Trichloride with Toluene and with Benzyl Chloride.-The solutions of the trichloride in toluene and the other aromatic liquids were prepared in much the same way as those in ethyl chloride had been. Five solutions in toluene were prepared totaling $1706 \mathrm{~g}$. of solution and containing $921.7 \mathrm{mg}$. atoms of nitrogen and $2633.5 \mathrm{mg}$. atoms of chlorine. The ratio of chlorine to nitrogen is 2.85. After preparation the solutions gradually became opalescent and in the course of 5 or 6 hours, quite warm. In 12 to 15 hours the reaction was evidently complete, unless the solution had been kept cool. In that case, 3 or 4 days were required. The white precipitate which formed in the toluene solution was found to be a mixture of ammonium chloride and the hydrochloride of the amines. From a solution containing $114 \mathrm{mg}$. atoms of nitrogen, about $1 \mathrm{~g}$. of free amine was found in the white precipitate and about an equal amount was secured from the toluene solution by treatment with conc. hydrochloric acid. Thus, only a small percentage of the total nitrogen present in the original solution was found in the amines. Of the remainder, about $3 / 4$ was evolved as free nitrogen and $1 / 4$ formed ammonium chloride. The toluene solution from the 5 preparations was found to contain 8 to $10 \mathrm{~g}$. of the monochloro-toluenes, and 10 to $12 \mathrm{~g}$. of benzyl chloride, with a

${ }^{15}$ Noyes, J. Am. Chem. Soc., 43, 2178 (1920). 
large residue boiling above $190^{\circ}$. These fractions were identified by boiling point and other properties.

In the study of the amines some of the tests made were the following. By the sodium-fusion method the substance was found to contain nitrogen and chlorine. When a sample was diazotized and mixed with an alkaline solution of $\beta$-naphthol, a bright reddish-yellow precipitate was formed. Carbon dioxide was passed into a dry ether solution, but no amine carbonate was precipitated, proving the absence of benzyl amine, $\mathrm{C}_{6} \mathrm{H}_{6} \mathrm{CH}_{2} \mathrm{NH}_{2}$. The isocyanide test indicated the presence of a primary amine. The reaction with benzene sulfonyl chloride also showed this. When some of the free amine product was boiled with ammonium hydroxide, chlorine was found to be present in the solution. When the liquid mixture of the free amines stood for a few days, it slowly changed to a hard, brittle solid.

When dry hydrogen chloride was passed into an anhydrous ether solution of the amines the hydrochlorides were readily formed as a white precipitate. The molecular weight was determined by solution in dil. nitric acid and precipitation of the chloride as silver chloride. Assuming the presence of only one amino group in the molecule this gave a molecular weight of 273.5. A nitrogen determination of the hydrochloride by the absolute method gave $5.04 \%$ of nitrogen. This agrees quite closely with the theory that the molecule contains but one amino group. The hydrochloride of tetrachloro-toluidine contains $4.98 \%$ of nitrogen; that of trichloro-toluidine $5.69 \%$.

Calc. for $\mathrm{C}_{7} \mathrm{H}_{3} \mathrm{Cl}_{4} \mathrm{NH}_{2} \mathrm{HCl}$ : $\mathrm{Cl}, 63.1$; Calc. for $\mathrm{C}_{7} \mathrm{H}_{4} \mathrm{Cl}_{3} \mathrm{NH}_{2} \mathrm{HCl}$ : $\mathrm{Cl}$, 57.5. Found: $\mathrm{Cl}$, 59.0.

The only important features of the work with benzyl chloride were the following. The reaction occurred much more slowly. No amine was found in the white precipitate, unless the solution had been exposed to sunlight, or allowed to stand a long time. The viscous liquid product gradually solidified as that from toluene had done.

III. Nitrogen Trichloride and Benzene.-The solutions were prepared in the usual way. This reaction took place much more slowly than did the reaction with toluene. The main chlorination product was benzene hexachloride. The white precipitate contained no amine, unless the solution was allowed to stand a long time or had been exposed to sunlight. The benzene solution from which the precipitate had been removed was shaken with enough sodium sulfite solution to remove any free chlorine. No amine, or at most only a trace, was found in the sulfite solution. The benzene solution did not now have the yellow color of free chlorine, nor did it liberate iodine from potassium iodide readily, as a solution of chlorine would, but only on prolonged shaking. This nearly colorless benzene solution was then shaken with conc. hydrochloric acid. The benzene turned yellow and readily liberated iodine from potassium iodide, and the aqueous layer was found to contain the amines. It was found that the benzene solution of this N-chloro-amine could be concentrated by vacuum distillation.

The amount of the amine mixture obtained was about the same as that from toluene. Most of the tests made with the amines from toluene were carried out with this product. A mixture of chloro-anilines was indicated. The viscous liquid mixture of the free amines did not solidify on standing; but on treatment with ether and ligroin gave a crystalline product. The hydrochloride was made by passing dry hydrogen chloride into an anhydrous ether solution. A molecular weight determination with this material gave 287. The molecular weight of the hydrochloride of tetrachloro-aniline is 267.5, and of pentachloro-aniline, 303.

\section{Summary.}

1. Nitrogen trichloride reacts with ethyl chloride to give, among other products, ethylene chloride. This compound is not a normal product of 
the action of free chlorine on ethyl chloride in the absence of a catalytic agent.

2. Nitrogen trichloride with toluene forms benzyl chloride and the monochloro-toluenes together with higher chlorinated derivatives.

3 . With benzene the main chlorination product is benzene hexachloride.

4. With toluene, with benzene, and with benzyl chloride, nitrogen trichloride forms small amounts of $\mathrm{N}$-chloro-amines.

5 . The N-chloro-amine group of the compounds formed from toluene and benzyl chloride is located in the nucleus and not in the side chain.

6. The chloro-amines at first formed are acted upon further by the nitrogen trichloride, or by chlorine, to give chlorinated chloro-amines. From benzene, the ultimate product is probably $\mathrm{C}$-pentachloro- $\mathrm{N}$-dichloroaniline $\mathrm{C}_{6} \mathrm{Cl}_{5} \mathrm{NCl}_{2}$ but such a compound was not isolated.

7. The chlorinations referred to take place at ordinary temperatures, and consequently are different from the rearrangements of chloro-amines studied by Chattaway and Orton. ${ }^{11}$ In this regard and also because all "of the hydrogen atoms of the benzene nucleus may be replaced by chlorine, they resemble the chlorination of aniline hydrochloride by chlorine. ${ }^{14}$

8 . The C-chloro-N-chloro-aniline liberates chlorine on treatment with conc. hydrochloric acid and is converted to C-chloro-aniline.

9. The facts established are most easily explained by assuming that the reactions are represented by the following equations.

$$
\begin{gathered}
\mathrm{C}_{6} \mathrm{H}_{6}+\mathrm{NCl}_{3}=\mathrm{Cl}\left(\mathrm{C}_{6} \mathrm{H}_{6}\right) \mathrm{NCl}_{2}=\mathrm{C}_{6} \mathrm{H}_{5} \mathrm{NCl}_{2}+\mathrm{HCl} \\
\mathrm{NCl}_{3}+4 \mathrm{HCl}=3 \mathrm{Cl}_{2}+\mathrm{NH}_{4} \mathrm{Cl} .
\end{gathered}
$$

10. The free chlorine from the last reaction would then chlorinate the chloro-amine.

11. The formation of hydrochloric acid under 9 involves a change of positive chlorine to negative, and the formation of considerable quantities of free nitrogen may be connected with this change. 
VITA.

Educational Career.

B. S. Greenville College, 1915.

M. S. University of Illinois, 1919.

Instructor in Chemistry and Physics.

Chesbrough Seminary, North Chili, N. Y., 191j-17.

Graduate Assistant in Chemistry, Univ. of I11., 1917-18.

Research Assistant in Chemistry, Univ. of I11., 1918-21.

\section{Publications.}

Work on the Conduct of Mixtures of Nitrogen and Chlorine in the

Flaming Arc. - $\quad$ - $\quad$ - $\quad$ - $\quad \therefore \quad W$. A. Noyes

J. Am. Chem. Soc , 43, 177t (1921). 

THIS BOOK IS DUE ON THE LAST DATE STAMPED BELOW

AN INITIAL FINE OF 25 CENTS WILL BE ASSESSED FOR FAILURE TO RETURN THIS BOOK ON THE DATE DUE. THE PENALTY WILL INCREASE TO 50 CENTS ON THE FOURTH DAY AND TOO \$1,00 ON THE SEVENTH DAY OVERDUE.

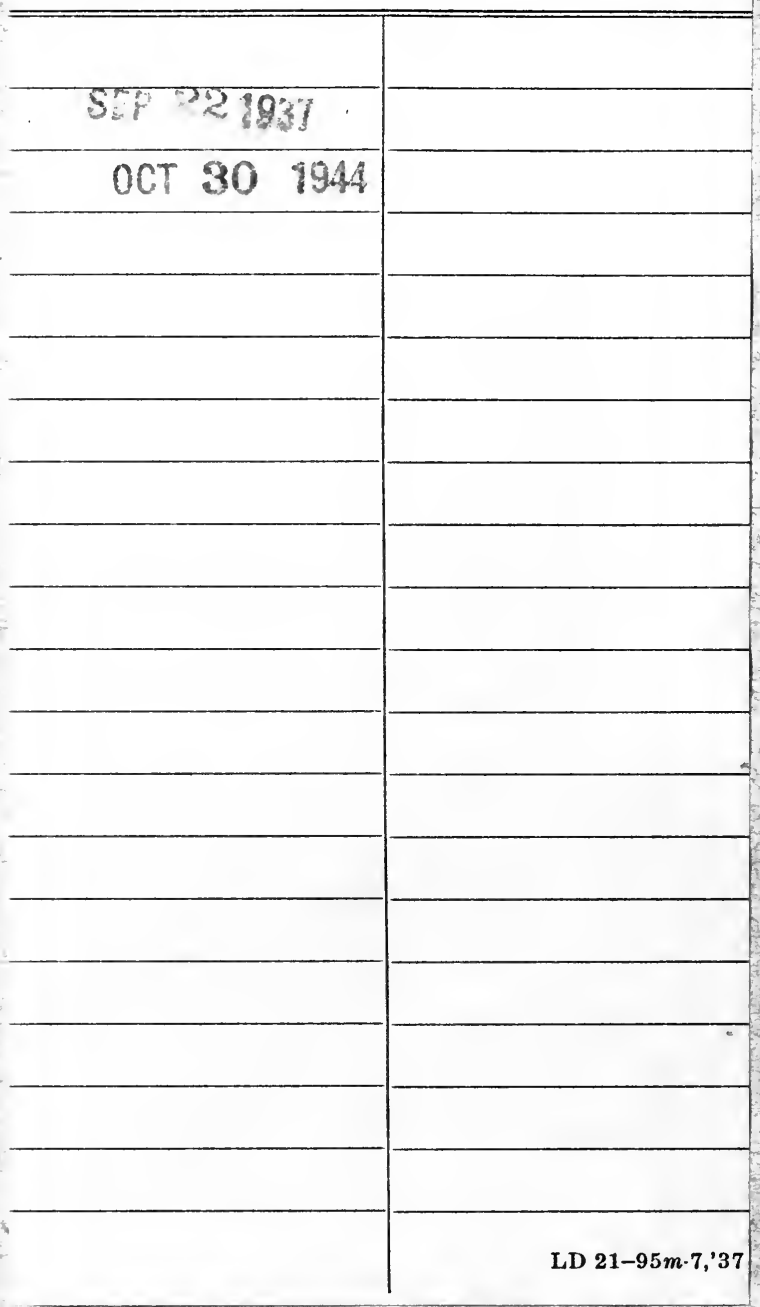


RETURN TO the circulation desk of any University of California Library

or to the

NORTHERN REGIONAL LIBRARY FACILITY Bldg. 400, Richmond Field Station University of California Richmond, CA 94804-4698

ALL BOOKS MAY BE RECALLED AFTER 7 DA

- 2-month loans may be renewed by calling (510) 642-6753

- 1-year loans may be recharged by bringing books to NRLF

- Renewals and recharges may be made 4 days prior to due date

\section{DUE AS STAMPED BELOW JUL 092004}


